\title{
Utopia ou realidade - a qualidade dos serviços prestados na Educação Infantil
}

Irene Antônia de Moura*

Adriana dos Santos Prado Sadoyama**

\section{Resumo}

O presente artigo aborda o tema utopia ou realidade com relação à qualidade dos serviços educacionais prestados na Educação Infantil, pois as transformações sociais e econômicas têm levado os consumidores a ficarem cada vez mais exigentes buscando instituições de ensino que ofereçam serviços de qualidade, que não exerçam somente o papel de cuidadores das crianças, mas que possibilitem a formação integral do ser. Ainda foi analisado se as politicas públicas e as propostas estabelecidas para atender as crianças pequenas são reais ou se são somente um conjunto de ideias utópicas as quais na prática não atingem os objetivos nem o público ao qual estão destinadas.

Palavras Chave: Educação Infantil. Qualidade em serviços educacionais. Utopia.

Irene Antônia de Moura. Licenciada em Pedagogia pelo Centro Universitário de Brasília (UNICEUB) Distrito Federal; Mestranda em Gestão Organizacional pela Universidade Federal de Goiás Campus Catalão - Goiás. E-mail: irene.antoniademoura@gmail.com

**Adriana dos Santos Prado Sadoyama. Professora da Universidade Federal de GoiásRegional de Catalão. Professora do Mestrado profissional em Gestão Organizacional. Formada em Letras e Pedagogia. drisadoyama@gmail.com 


\section{Introdução}

Desde Platão até os dias de hoje o homem imagina e busca criar um modelo ideal de sociedade, pautada na justiça e igualdade de direitos, como consta na Constituição Federal de $1988 \mathrm{em}$ seu artigo 6 de acordo com a Emenda Constitucional n ${ }^{\circ} 90$ de 2015, estabelece o Estado Democrático, visando garantir os direitos sociais (educação, saúde, alimentação, trabalho, moradia transporte, lazer, segurança, previdência social, a proteção à maternidade e a infância, assistência aos desamparados) e individuais sem sofrer nenhuma forma de preconceito.

Analisando o conteúdo desse artigo constitucional nota-se que as primeiras palavras do texto da introdução vêm carregadas de ideias utópicas, onde é idealizado um modelo social e político que ainda não é totalmente real. Os indivíduos sequer compreendem plenamente o significado e o teor dessas ideias, e que a Lei não se cumpre por si mesma, que para isso é necessário ação e trabalho de todos principalmente dos envolvidos diretos, os gestores, nesse caso os que foram escolhidos para colocar em prática o que foi estabelecido em Lei. Diante do exposto no artigo $6^{\circ}$ da Constituição Federal de 1988 será discutido apenas um dos direitos sociais: a educação. Direito esse que não é exercido de forma igualitária por todos os cidadãos brasileiros, onde os mais pobres e o público infantil de zero a cinco anos muitas vezes não tem acesso a creches e escolas de qualidade como constata Correa (2011) em seus estudos descrevendo que o acesso desse público à Educação Infantil foi fruto de muitas lutas e batalhas da população. Assim, diante dessa realidade perguntase: o acesso a uma escola de qualidade de fato é uma realidade ou uma utopia?

Com a finalidade de responder a esse questionamento foi elaborado esse artigo cujo objetivo é verificar se a qualidade nos serviços educacionais prestados na Educação Infantil é uma utopia ou realidade.

Para a composição do mesmo foi realizado uma revisão bibliográfica, analisando vários artigos com o tema proposto, livros, a Constituição Federal de 1988, a Lei de Diretrizes e Bases de 1996. Usando como base de busca de dados Scielo, ANPAD, RAE - Revista de Administração Empresarial, trabalhos realizados em Institutos de estudos e pesquisas por universidades. 


\section{Desenvolvimento}

\section{Utopia e realidade}

Diante do cenário político, econômico e social brasileiro observa-se que o mundo real é diferente do mundo idealizado e propagado. Nesse sentido Silva (2016) expõe que é insuficiente ter uma intenção, uma ideia ou o propósito de fazer algo, é necessário romper com o que já existe e está em desarmonia, que não atende as reais necessidades dos indivíduos. Nesse caso são os modelos de políticas públicas e programas voltados para a Educação Infantil, os quais estão presentes, existem, mas não são suficientes para promover a qualidade nos serviços educacionais prestados.

Nesse sentido, de acordo com Fontana (2014) falar de qualidade nos serviços educacionais prestados na Educação Infantil significa uma utopia, uma vez que o modelo de programa proposto apresenta-se insatisfatório, pois não atende as reais necessidades das crianças pequenas. Diante desse argumento Felipe (1979) define utopia como "algo que não existe e/ou o de algo difícil de ser concretizado. Do grego, u =não existente e topos= lugar" (FELIPE 1979, p.69). Tratando-se do sistema educacional pode-se mencionar que as instituições ainda não têm condições de proporcionar um serviço de qualidade aos educandos.

Para Araújo (2009) utopia "é um processo histórico e dialético". "É um projeto que se concretiza em ações. Significa os desejos e aspirações individuais ou pelo menos, de uma ampla parcela da sociedade" (ARAÚJO 2009, p.10). Em outras palavras leis e propostas são elaboradas, aprovadas, mas dificilmente são cumpridas na integra. Como cita More (1993) "comparo Utopia com países que fazem leis sem cessar, e não obstante são sempre incapazes de solucionar seus problemas" (MORE 1993, p. 57). Considerando tais colocações a solução possível para a resolução dos problemas enfrentados por um país está em priorizar a educação realizando o que determina a Carta Magna, ou seja, transformar em realidade o que hoje é considerada uma utopia.

\subsection{Educação e qualidade dos serviços educacionais}

Segundo Vieira (2012), a educação é um direito inseparável da natureza humana, o qual garante o desenvolvimento das capacidades e potencialidades do ser humano, uma vez que no processo educacional estão envolvidos vários 
aspectos como: a construção da cidadania, de valores sociais, desenvolvimento intelectual, psicológico e moral favorecendo a formação plena do ser. A sociedade que privilegia a educação está alicerçada numa base muito mais sólida, consubstanciada em um modelo centrado no respeito aos direitos e garantias fundamentais, os quais estão garantidos na Constituição brasileira de $1988 \mathrm{em}$ seu artigo 205, o qual retrata a educação como um direito de todo cidadão e por isso dever do Estado e da família promover, incentivar e colaborar social, política e economicamente para que a pessoa se desenvolva e seja preparada para exercer seu papel de cidadão qualificado para o trabalho.

Sendo a educação um direito de todos, como consta na Constituição federal de 1988 deve ser orientada pelo critério da universalidade, entendida sob o prisma dos princípios constitucionais, tanto os princípios que enfocam o caráter social do Estado Democrático, quanto os direcionados especificamente para a educação básica - Educação Infantil e Ensino Fundamental e Ensino Médio.

Ainda sobre esse tema a Constituição Federal de 1988 trás em seus artigos 208 e 211 os princípios gerais da Ordem Social estabelecendo o dever do Estado, obrigando-o a ofertar gratuitamente os serviços educacionais para as crianças de 0 (zero) aos 17 (dezessete) anos, além daqueles que não tiveram oportunidade de estudar nessa faixa etária. Também deve atender aos educandos provendo-os com materiais didáticos, transporte escolar, alimentação e assistência à saúde.

Além da Constituição Federal de 1988, a Lei oo 9.394 de 1996 - Lei de Diretrizes e Bases da Educação Nacional (LDB) regulamenta a educação brasileira, principalmente o que está relacionado ao Sistema de Ensino Público e Particular e também os princípios do direito à educação e sua organização. Segundo Ramos (2013), a LDB de 1996, cita que a União, os Estados, o Distrito Federal e os Municípios organizam conjuntamente habilidades, normas procedimentos que norteiam as ações curriculares a serem desenvolvidas na Educação Infantil e no Ensino Fundamental e Médio com a finalidade de garantir a formação básica comum.

Entretanto, o Brasil tem enfrentado grandes desafios para colocar em prática o que está estabelecido na lei com relação à educação. Para que todas as exigências legais sejam cumpridas faz-se necessário uma organização por meio de um planejamento bem elaborado, dinâmico, executável, dialógico, flexível, inclusivo, possibilitando que o ensino ofertado e os serviços educacionais prestados sejam de 
qualidade e atendam aos interesses e necessidades dos educandos, favorecendo assim uma formação educacional de qualidade ao cidadão brasileiro.

Nesse sentido, Campos (2012), observa que é necessário vencer muitos obstáculos, planejar criteriosamente as ações, investir e rever políticas públicas voltadas para a área educacional, formar e capacitar profissionais da educação, modernização tecnológica na área educacional, construção e ampliação de mais unidades escolares como Creches e Centros de Educação Infantil para atender às crianças da Educação Infantil, viabilizando as condições de funcionamento desses estabelecimentos, observando os cuidados com a infraestrutura, alimentação, saúde, condições de trabalho, remuneração, formação continuada dos profissionais e adaptação curricular para atender essas crianças.

Nos últimos anos observa-se que o Brasil vem enfrentando estagnação econômica, crises políticas, corrupção, falta de expansão do mercado de trabalho e crescente aumento das exigências formais de qualificação para os trabalhadores. Fatores que contribuem para acarretar a má qualidade educacional pública, levando e acentuando a exclusão social, onde o principal ator é o aluno que é discriminado socialmente por depender de uma escola pública que não o insere de forma igualitária em uma sociedade altamente competitiva.

E a etapa mais atingida por esses fatores é a Educação Infantil, mesmo sendo um direito garantido por lei ainda não é considerada prioridade, como descreve Morgan; Silva; Knackfuss e Medeiros, (2014), havendo dissonância entre o que foi estabelecido em lei e o que de fato ocorre na realidade. Ainda citam que com a finalidade de melhorar o retrato da Educação Infantil no país, o Estado lança por meio do Ministério da Educação e Cultura (MEC) o Prêmio de Qualidade da Educação Infantil, o qual não surte o efeito esperado e ainda coloca sobre o professor o peso e a responsabilidade de desenvolver e promover um trabalho de qualidade em sala de aula. Algo que independe da vontade e do trabalho desenvolvido exclusivamente do educador, uma vez que a qualidade nos serviços prestados depende de todo um sistema composto por União, Estado, Municípios e comunidade escolar.

Considerando tais colocações Libâneo (2004) define que educação de qualidade é aquela que promove a inclusão social do indivíduo por meio do desenvolvimento das habilidades e competências cognitivas, operativas e psicossociais auxiliando-o em sua formação e na construção do ser como sujeito. 
Dourado (2014) define qualidade como a decorrência do desempenho demonstrado pelo educando durante o processo de ensino e aprendizagem. Desempenho este que é mensurado por meio de avalições e pesquisas propostas pela instituição durante o processo de formação do indivíduo. Também conforme Parasuraman; Zeithaml; Berry (2006) qualidade de serviço pode ser considerada como um parâmetro para avaliar o nível de excelência percebido pelo cliente quanto à prestação de um serviço e se o mesmo atendeu sua expectativa.

Nesse sentido, Kotler (1998) discrimina serviço como "qualquer ato ou desempenho que uma parte pode oferecer a outra e que seja essencialmente intangível e não resulte na propriedade de nada. Sua produção pode ou não está vinculada a um produto físico" (KOTLER,1998, p.412). Nesse contexto essa definição pode ser utilizada para discriminar os serviços prestados na área educacional, onde um serviço é ofertado e realizado, mas que o produto final não é considerado um produto físico, tangível. Assim, de acordo com Lobo; Duque; Oliveira; Rodrigues (2008), serviço pode ser descrito como ações executadas por uma corporação com o intuito de atender as demandas demonstradas pelos indivíduos de uma determinada comunidade. Ele também define qualidade em serviços como sendo o nível de satisfação esperado e alcançado pelo indivíduo ao buscar algum tipo de serviço, onde seus anseios sejam satisfeitos por meio de atitudes que permitam perceber e mensurar a qualidade ou não do serviço prestado.

Para que os serviços educacionais prestados na Educação Infantil atendam as expectativas e sejam de fato de qualidade, além das mudanças já citadas é preciso propor ao sistema educacional brasileiro a gestão democrática que é descrita por Gadotti e Romão (2012): a unificação e descentralização do sistema educacional com propósitos bem definidos com a finalidade de inovar as estratégias educacionais permitindo a acessibilidade e o envolvimento de toda a comunidade escolar desintegrando uma forma de poder hierarquizado e verticalizado, ou seja, eliminando o autoritarismo e centralização das decisões, rompendo com a cultura de descontinuidade dos trabalhos e projetos voltados para a área educacional, quando ocorre uma mudança de governo.

Dessa forma, analisando a educação como um fator de mudanças sociais é preciso buscar incansavelmente oferecer um serviço de qualidade com objetivos e metas claras, bem definidas integrando governo, sociedade e instituições de ensino, pois somente assim todos juntos olhando e caminhando na mesma direção tendo 
como foco a qualidade nos serviços prestados na educação será possível transformar ideais e sonhos em realidade.

\subsection{Educação Infantil}

Na Europa, no século XVIII, a revolução industrial cedeu lugar à mão de obra feminina, ocorrendo assim, a saída das mães para trabalhar nas fábricas. Nesse período também iniciou a transformação do núcleo familiar, que de extenso passa a ser nuclear. Sendo que antes as crianças pequenas eram cuidadas pelos avós, tios, primos e irmãos maiores, entretanto com o advento das fábricas as pessoas foram convocadas a trabalhar, e essas crianças passaram a ser deixadas sozinhas. Fato que de acordo com Didonet (2001) ocasionou a elevação de morte de crianças, desnutrição e acidentes no ambiente doméstico, o que despertou a atenção e um espirito de solidariedade da comunidade. Permitindo que essas crianças comecem a serem vistas socialmente e de forma filantrópica, assistencialista, caritativa iniciando um processo de atendimento das mesmas fora do âmbito familiar. Ainda de acordo com Didonet (2001), nesse momento surgiram os primeiros abrigos para crianças que eram denominados como: garderie, na França; asili, na Itália; écoles gardiennes, na Bélgica. Até hoje em alguns países da América latina usa-se a expressão guardería (guarda de criança), referindo-se a crianças de 0 a 3 anos. Tal expressão foi utilizada também no Brasil para as primeiras creches impostas por meio da Consolidação das Leis Trabalhistas (CLT) em 1943, que segundo Didonet (2001), essa lei determinava que as empresas as quais possuíssem mais de 30 mulheres trabalhando deveriam dispor de um lugar para guardar as crianças enquanto ainda amamentassem, surgindo às primeiras creches, que atendiam as crianças das mães trabalhadoras, em tempo integral, gratuitamente ou cobrando um valor irrisório. Esse modelo de creche brasileiro assemelhava ao modelo europeu com uma diferença que no Brasil, era atendido crianças órfãs, abandonadas ou de mães solteiras (modelo assistencialista e filantrópico).

Ainda citando Didonet (2001) no Brasil existem creches com esse perfil as quais se preocupam com o cuidado com as crianças deixando de lado a parte pedagógica, entretanto existem muitas instituições infantis que não somente cuidam, mas tem um planejamento e um trabalho pedagógico "fundamentado nas ciências 
pertinentes, com profissionais qualificados, que seguem critérios de qualidade e que fazem avaliação de desempenho" (DIDONET, 2001, p.13).

Portanto, observa-se que até 0 inicio do século $X X$ não havia tanta preocupação com as crianças pequenas, mas com o processo de industrialização e com a mudança do cenário social e familiar houve a necessidade de criar espaços específicos onde às crianças fossem cuidadas enquanto a mãe estava fora. Como descreve Gomes e Costa Filho (2013) durante o império já existiam as creches, entretanto, elas ganharam mais atenção por parte das entidades governamentais nos anos setenta. Até então a educação infantil era vista de forma assistencialista, filantrópica, sem considerar os aspectos educacionais. Entretanto, com a elaboração da Lei de Diretrizes e Bases da Educação, ocorreram mudanças e reestruturação politicas e econômicas.

\section{CONSIDERAÇÕES FINAIS}

Este artigo foi elaborado com a finalidade verificar se a qualidade nos serviços educacionais prestados na educação infantil é uma utopia ou realidade, averiguou-se que as pesquisas e os estudos realizados nos últimos anos constataram que há muito a se fazer para que a qualidade nos serviços educacionais prestados na educação infantil deixe de ser uma utopia, um desejo ou um ideal a ser atingido e se torne de fato uma realidade. Várias mudanças ainda são necessárias, pois não é somente uma questão de idealização ou projeção, mais importante que isso é a ação, a qual deve ser pautada em projetos bem elaborados e possíveis de serem realizados. Dentre essas ações cita-se a elaboração de políticas públicas coesas, formação e capacitação específicas para os profissionais que atuam nessa área, cumprimento da legislação voltada para a educação infantil; planejamento e investimento financeiro que atenda as reais necessidades das instituições educacionais, construção de mais escolas, foco na gestão administrativa escolar, planejamento institucional onde toda a comunidade escolar participe e seja envolvida nas ações desenvolvidas pela instituição.

Também foi possível constatar que é necessário conhecimento mais sistematizado sobre o desenvolvimento infantil e a Educação Infantil, por mais que se estude ainda há muito que aprender. Somente por meio do estudo, da pesquisa, 
da participação e colaboração de todos os envolvidos com o sistema educacional será possível elaborar propostas e projetos pedagógicos capazes de abranger as reais necessidades das crianças, possibilitando a formação de um sujeito apto a interagir e relacionar com autonomia e independência com o meio ao qual está inserido.

Além desses aspectos faz-se necessário conhecer a opinião dos usuários dos serviços educacionais, uma vez que ao conhecer o pensamento e o nível de satisfação dos mesmos é possível promover a melhoria constante e o aprimoramento dos serviços prestados pela instituição. Mais pesquisas podem ser realizadas com base no tema proposto uma vez que ainda há muito a ser descoberto com relação à utopia e a realidade na qualidade dos serviços educacionais. Durante a pesquisa percebeu-se que quase não existem artigos sobre o tema utopia voltados para a área educacional, e que desde os primeiros escritos relacionados a esse assunto a questão da qualidade ainda continua sendo considerado algo quase impossível de ser atingido e que os seres humanos estão continuamente a imaginar e a projetar mudanças, entretanto são criaturas resistentes ao novo, em romper com velhos paradigmas. 
English Title: Utopia or reality the quality of services provided in kindergarten.

\section{Abstract}

This article is about utopia or reality regarding the quality of educational services in early childhood education, for social and economic changes have led consumed become increasingly demanding seeking educational institutions that offer quality services, which do not exercise only the role of caregivers of children, but that allow the integral formation of . Yet it was examined whether public policies and proposals set out to meet the young children are real or if they are only a set of utopian ideas which in practice does not affect the objectives or the public to which they are intended.

Keywords: Children's Educational; Quality in educational services; Utopia.

\section{Referências}

ARAÚJO, Rogério Bianchi. A utopia como representação social da realidade. OPSIS, Catalão, v. 9, n. 12,.jan-jun 2009.

BRASIL. Constituição da República Federativa do Brasil. Brasília: Senado Federal, 1988.

BRASIL. Lei n. 9.394, de 20 de dezembro de 1996. Dispõe sobre as Diretrizes e Bases da Educação Nacional. Diário Oficial da União, Brasília, DF, 23 dez. 1996.

CAMPOS, M. Malta. ESPOSITO, Yara. BHERING, Eliana. GIMENES, Nelson. ABUCHAIM, Beatriz. FERNANDES, F. Silva. RIBEIRO, Bruna. A gestão da Educação Infantil no Brasil. Este estudo foi realizado pela Fundação Carlos Chagas (FCC) sob encomenda da Fundação Victor Civita (FVC). 12/18/12. 2 Estudos \& Pesquisas Educacionais - Fundação Victor Civita.

CORREA, B. C. Políticas de educação infantil no Brasil: ensaio sobre os desafios para a concretização de um direito. Jornal de políticas educacionais. $n^{\circ}$ 9, janeiro-junho de 2011. p. $20-29$. 
DIDONET, Vital. Creche: a que veio, para onde vai. In: Educação Infantil: a creche, um bom começo. Em Aberto/Instituto Nacional de Estudos e Pesquisas Educacionais. v 18, n. 73. Brasília, 2001. p.11-28.

DOURADO, Luiz Fernando. OLIVEIRA, João Ferreira de. A qualidade da educação: Conceitos e definições. Brasil - Ministério da Educação, Instituto Nacional de Estudos e Pesquisas Educacionais Anísio Teixeira, 2014, p.43.

FELIPE, Sônia Terezinha. O Conceito de Utopia na proposta Paulofreireana. Departamento de Filosofia - Universidade Federal de Santa Catarina; 1979.

FONTANA, Ingrid Leão Mendes. Polemizando o processo das Políticas Públicas para a Educação Infantil. X ANPED SUL, Florianópolis, outubro de 2014.

GADOTTI, Moacir. ROMÃO, J. Eustáquio. Autonomia da Escola - princípios e propostas. 7ª edição, São Paulo, SP. Cortez, 2012.

GOMES, E. S.; COSTA FILHO, J. Historicidade da infância no Brasil. El Futuro del Pasado, no 4, 2013, p. 255-276. ISSN: 1989-9289.

KOTLER, P. Administração de marketing. Tradução de Ailton Bomfim Brandão. 5 a $^{\text {a }}$ ed. São Paulo: Atlas, 1998.

LIBÂNEO, J. Carlos. Organização e Gestão da Escola: Teoria e Prática. 5ª edição revista e ampliada - Goiânia - GO; Editora Alternativa, 2004.

LOBO, J. R. Marques; DUQUE, L. Polisseni; OLIVEIRA, L. O. de Freitas; RODRIGUES,M. V. Y Rodrigues; O uso da Escala SERVQUAL para avaliar a percepção de valor na prestação de serviços de manutenção de computadores. IV CONGRESSO NACIONAL DE EXCELÊNCIA EM GESTÃO Responsabilidade Socioambiental das Organizações Brasileiras. Niterói, RJ, Brasil, 31 de julho, 01 e 02 de agosto de 2008.

MORE, Thomas. Utopia. São Paulo: Martins Fontes, 1993.

MORGAN, Dimas Anaximandro da Rocha. SILVA, Joelma Gomes. KNACKFUSSC, Maria Irany. MEDEIROS, Humberto Jefferson. As políticas públicas no contexto 
da Educação Infantil brasileira. Construção Psicopedagógica; v22 n23: 51-58; 2014.

PARASURAMAN, A. ZEITHAML, Valarie A. BERRY, Leonard L. Um modelo conceitual de qualidade de serviço e suas implicações para a pesquisa no futuro. RAE - Revista de Administração de Empresas. V.46, nำ, 2006.

RAMOS, Z. Leite. Conhecimentos Pedagógicos; 6a edição - Brasília: Vesticon. 2013, p.405.

SILVA, Antônio Ozaí. Utopias, ideologias e o “leito de Procusto”. Revista Espaço Acadêmico no 182. Ano XVI; julho de 2016.

VIEIRA, Andréa Zacarias. O regime constitucional do direito à educação básica. In: Âmbito Jurídico, Rio Grande, XV, n. 106, nov 2012. 